\title{
In situ detection of electrified aerosols in the upper troposphere and stratosphere
}

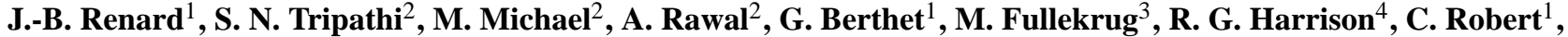 \\ M. Tagger ${ }^{1}$, and B. Gaubicher ${ }^{1}$ \\ ${ }^{1}$ LPC2E-CNRS/University of Orléans, 3A avenue de la recherche scientifique, UMR7328, 45071 Orléans cedex 2, France \\ ${ }^{2}$ Indian Institute of Technology, Kanpur, Center for Environmental Science and Engineering, Kanpur, India \\ ${ }^{3}$ University of Bath, Department of Electronic and Electrical Engineering, Claverton Down, Bath, BA2 7AY, UK \\ ${ }^{4}$ University of Reading, Department of Meteorology, Reading RG6 6BB, UK
}

Correspondence to: J.-B. Renard (jean-baptiste.renard@cnrs-orleans.fr)

Received: 16 December 2012 - Published in Atmos. Chem. Phys. Discuss.: 18 March 2013

Revised: 17 August 2013 - Accepted: 16 October 2013 - Published: 18 November 2013

\begin{abstract}
Electrified aerosols have been observed in the lower troposphere and in the mesosphere, but have never been detected in the stratosphere and upper troposphere. We present measurements of aerosols obtained during a balloon flight to an altitude of $\sim 24 \mathrm{~km}$. The measurements were performed with an improved version of the Stratospheric and Tropospheric Aerosol Counter (STAC) aerosol counter dedicated to the search for charged aerosols. It is found that most of the aerosols are charged in the upper troposphere for altitudes below $10 \mathrm{~km}$ and in the stratosphere for altitudes above $20 \mathrm{~km}$. Conversely, the aerosols seem to be uncharged between $10 \mathrm{~km}$ and $20 \mathrm{~km}$. Model calculations are used to quantify the electrification of the aerosols with a stratospheric aerosol-ion model. The percentages of charged aerosols obtained with model calculations are in excellent agreement with the observations below $10 \mathrm{~km}$ and above $20 \mathrm{~km}$. However, the model cannot reproduce the absence of electrification found in the lower stratosphere, as the processes leading to neutralisation in this altitude range are unknown. The presence of sporadic transient layers of electrified aerosol in the upper troposphere and in the stratosphere could have significant implications for sprite formation.
\end{abstract}

\section{Introduction}

The origin and characteristics of aerosols in the earth's atmosphere vary considerably. For example, a large variety of natural and anthropogenic particles (e.g. sulfates, soot, minerals, etc.) with a complex chemistry (e.g. Tie et al., 2005) are found in the troposphere. In the stratosphere, liquid aerosols originate from gases like carbonyl sulfide (OCS) (Brühl et al., 2012) and sulfur dioxide $\left(\mathrm{SO}_{2}\right)$, which are released during volcanic eruptions (Haywood et al., 2010). The eruption of the Mount Pinatubo in 1991 strongly increased the stratospheric aerosol content for several years (Deshler et al., 2003). Numerous smaller volcanic eruptions help to sustain the "background" aerosol content in the stratosphere (Vernier et al., 2011). In addition to liquid aerosols, solid particles have been detected in the lower and middle stratosphere (Renard et al., 2008; Ciucci et al., 2008; Neely et al., 2011). Stratospheric soot particles mainly originate from biomass burning injected into the stratosphere by pyroconvection (Fromm and Servranckx, 2003). Soot particles are also speculated to originate from anthropogenic activities (Schwarz et al., 2006). Aerosols from meteoritic debris (e.g. Klekociuk et al., 2005) and interplanetary grains are present at all altitudes, with occasional local and temporal enhancements. Such solid particles may explain the sporadic aerosol layer detected above $30 \mathrm{~km}$ by Renard et al. (2010). Finally, in the mesosphere, the recondensation of disintegrated meteoritic material produces "smoke particles" (Gabrielli et al., 2004; Amyx et al., 2008; Herving et al., 2009).

Some of these aerosols are electrified, and have been studied in the troposphere and in the mesosphere. In disturbed weather in the troposphere, droplets can be charged within thunderstorms and electrified shower clouds, but even in the fair weather atmosphere, aerosol particles can be charged 
from ion diffusion (Gunn, 1954; Keefe et al., 1959; Clement and Harrison, 1991). Accordingly we expect a proportion of aerosol particles to be charged, depending on the local ion concentrations and temperature. Droplet charging at horizontal edges of stratiform clouds is attributed to vertical current flow associated with cosmic ray ionisation (Nicoll and Harrison, 2010). Electric discharges and charges have also been detected in volcanic ash (Gilbert et al., 1991; Harrison et al., 2010) and in Saharan dust layers (Nicoll et al., 2011). These aerosols become electrified under the influence of natural atmospheric electricity. In the mesosphere, smoke and ice particles are part of the plasma in the D-region and carry positive and negative charges (Hoppe et al., 1999; Rapp, 2009).

In contrast with the troposphere and mesosphere, charging of liquid and solid particles in the stratosphere has received little attention. This paper describes the first in situ measurements of electrified aerosols in the stratosphere, which are compared with theoretical model calculations. The implications of these observations are discussed in the context of the global atmospheric electric circuit.

\section{Measurement technique of uncharged and charged aerosols}

in situ measurements of aerosols have been obtained by use of the optical Stratospheric and Tropospheric Aerosol Counter (STAC) on board a stratospheric balloon payload (Renard et al., 2008). The STAC instrument measures the light scattered by individual particles or droplets as they cross a laser beam at a scattering angle of $70^{\circ} \pm 35^{\circ}$. The intensity of the scattered light is proportional to aerosol size. (For calibration, latex beads having diameters from 0.4 to $5 \mu \mathrm{m}$ were used.) Counting the pulses of scattered light provides aerosol concentration data in 13 size classes chosen in the 0.33 to $5.5 \mu \mathrm{m}$ size range (Fig. 1). The instrument has been optimised for observation of liquid droplets, with an uncertainty in size determination of $3 \%$. For solid particles, which have non-zero values of the imaginary part of the refractive index because of their absorbing properties, the intensity of the scattered light is less than that for the liquid droplets. This means that the concentration for a given size class can be underestimated, because the concentration of solid aerosols is attributed to lower size classes (Renard et al., 2010).

Samples of atmospheric air are pumped through the instrument continuously at $3 \mathrm{~L}$ per minute. Taking into account the pump efficiency and the noise in the optical detector, the counting uncertainty is $\pm 30 \%$ for concentrations smaller than $10^{-3} \mathrm{~cm}^{-3}$, and falls to $\pm 10 \%$ for concentrations around $10^{-1} \mathrm{~cm}^{-3}$, and is reduced further to $\pm 3 \%$ for concentrations larger than $1 \mathrm{~cm}^{-3}$ (Ovarlez and Ovarlez, 1995). The lower limit of concentration is around $10^{-4} \mathrm{~cm}^{-3}$, which corresponds to $\sim 5 \times 10^{-5} \mathrm{~cm}^{-3} \mu \mathrm{m}^{-1}$ for the largest particles that can be detected by STAC $(\sim 5 \mu \mathrm{m})$. However, laboratory comparisons between two copies of the STAC aerosol

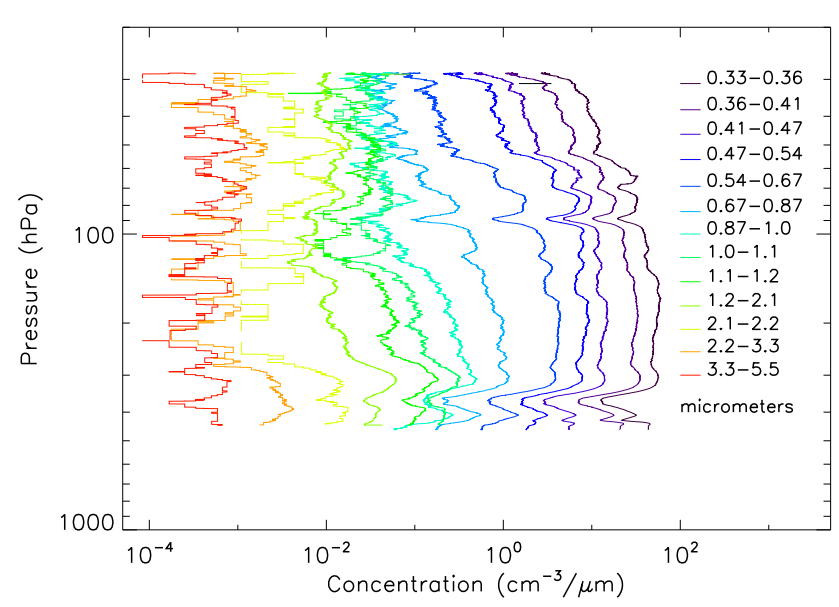

Fig. 1. Vertical profiles of the charged and uncharged aerosol concentration, on 12 March 2011 from Kiruna (northern Sweden) during the balloon ascent.

counter using identical aerosol samples have shown differences of $\pm 10 \%$ for concentrations higher than $10^{-2} \mathrm{~cm}^{-3}$. From these results, we define a measurement precision limited to $\pm 10 \%$. Note that comparisons with the aerosol concentrations measured by the University of Wyoming optical particle counter (Deshler et al., 2003) conducted several years ago have shown consistent results between all instruments (Renard et al., 2002).

STAC was designed to be mechanically insensitive to pressure and temperature changes. No thermal effect on the measurement electronics has been detected during flights but, for the flight reported here, the instruments were operated inside a gondola to protect them from the low atmospheric temperatures, with only their inlets and the electric trap outside.

In its usual form, STAC cannot distinguish charged and uncharged aerosols. Therefore an electric trap was added to remove charged particles, which is mounted between the air inlet and the optical chamber. The electric trap is based on multiple plate-shaped electrodes spaced from each other by $5 \mathrm{~mm}$. By applying a potential of $220 \mathrm{~V}$ between two consecutive electrodes, a deflecting electric field of $45 \mathrm{kV} \mathrm{m}^{-1}$ is generated. Particles are pumped through the electric trap under laminar gas-flow conditions, at a flow speed of $33 \mathrm{~mm} \mathrm{~s}^{-1}$. For particle radii from $0.3 \mu \mathrm{m}$ to a few $\mu \mathrm{m}$ with the bulk densities expected for stratospheric aerosols, the time to reach the maximum speed $\left(\sim 1 \mathrm{~mm} \mathrm{~s}^{-1}\right)$ within the electric field is of a few microseconds. The calculations assume that the aerosols levitate in the atmospheric electric field; then $\sim 8$ electrons are present in a $0.3 \mu \mathrm{m}$ particle, and $\sim 8000$ electrons are present in a $3 \mu \mathrm{m}$ particle.

The trap will therefore remove charged aerosols, and only allow the uncharged aerosols emerging to enter the optical detection chamber of the aerosol counter. Even so, some charged aerosols may remain despite the trap, for example under anomalously large stratospheric aerosol 
concentrations. Hence the conservative view should be adopted that the measurements only provide a lower limit on the charged particle concentration.

During the experiments, two identical STAC instruments were operated simultaneously on the same balloon gondola: one with the electric trap to measure the concentration of uncharged aerosols, and one without the trap to measure the total aerosol concentration. The concentration of charged particles was calculated by subtracting the counts of the two instruments. This method determines the concentration of charged aerosols - and therefore the proportion of aerosols charged - but not the polarity. Because the two instruments respond symmetrically, the comparison of the relative counts from the two STAC instruments is unaffected by the presence of solid particles.

Laboratory tests were conducted to verify consistency between the two instruments working simultaneously with and without the electric trap. Tests were performed in surface ambient air, with and without the electric trap. For the tests with the electric trap, the ambient measurements were performed with air containing both liquid and solid aerosols, and then with different solid particles (carbon, sand, dust) dispersed into the air. All these aerosols were assumed to be negligibly charged. This is a reasonable assumption in normal ambient air with no abnormal electrical atmospheric activities. For all the surface tests, the two counters give the same concentrations within the uncertainties given above, for the different size classes in the $0.33-5.5 \mu \mathrm{m}$ size range. These tests confirm that the presence of the electric trap does not bias the measurements for the aerosols assumed to be nonelectrified. Nevertheless, the possibility remains that some electrified particles were present during these tests, and that some electrified particles were not sampled during the flight measurements. Accordingly, we could consider the electrified particle concentrations as lower limits.

\section{Vertical profiles}

A stratospheric balloon carrying the two STAC instruments was launched by the French space agency CNES on 12 March 2011, from Kiruna, northern Sweden $\left(67^{\circ} 53^{\prime} \mathrm{N}, 21^{\circ} 04^{\prime} \mathrm{E}\right)$. The balloon flight lasted from 20:00 to 22:05 UTC. Measurements with the STAC instruments were conducted during the ascent in the $480-28 \mathrm{hPa}$ altitude range and during the slow descent in the $28-130 \mathrm{hPa}$ altitude range with the vertical speed in the range of $2-5 \mathrm{~m} \mathrm{~s}^{-1}$. STAC sampled the aerosol data once per second. Measurements were integrated over $75 \mathrm{~s}$, which provides a good compromise between removing local fluctuations whilst permitting detection of vertical structures. This timescale corresponds to $\sim 300 \mathrm{~m}$ vertically, depending on the balloon ascent or descent rate.

Figure 1 shows the measurement of uncharged aerosol concentrations during the measurement process as described above. Similar curves were obtained during the descent. The flight was performed during representative conditions of aerosol content, i.e. with the smallest particles' concentrations decreasing with altitude and a maximum concentration around the tropopause (located here around the $\sim 300 \mathrm{hPa}$ level, corresponding to an altitude of $\sim 8 \mathrm{~km}$ ). The rate of change of the size distribution for aerosols larger than $1 \mu \mathrm{m}$ in comparison with smaller sizes is expected to indicate the presence of solid particles. This approximately constant concentration of large solid particles has been observed previously (Renard et al., 2010).

Measured concentrations are summarised in three size classes: $0.35-1 \mu \mathrm{m}, 1-3 \mu \mathrm{m}$, and $3-5 \mu \mathrm{m}$. These class sizes are related to the nature of aerosols and to their evolution with altitude. Liquid aerosols dominate in the sub-micron size range, whereas aerosol larger than $1 \mu \mathrm{m}$ could be solid particles. The third size class corresponds to aerosols having more or less a constant concentration in the observed stratosphere and troposphere, such as background interplanetary dust. It can be noticed that these very low concentrations are not constant at small vertical scale, thus producing oscillations in the vertical profile.

Figure 2 presents the vertical profiles of concentrations for all aerosols and for uncharged aerosols in the three size classes (left), and the fraction (in \%) of charged aerosols (right), taking into account the known uncertainties. It is noted that the measurements during the ascent and the descent are in excellent agreement with the concentrations for both uncharged and charged aerosols, except close to the tropopause where some small discrepancies occur. The smaller two size classes exhibit the same dependence on altitude: most of the aerosols are electrified in the upper troposphere for altitudes up to $10 \mathrm{~km}$ (pressure $>200 \mathrm{hPa}$ ) and in the middle stratosphere for altitudes down to $20 \mathrm{~km}$ (pressure $<50 \mathrm{hPa}$ ). The proportion of electrified aerosols reaches $40 \%$ for sub-micron aerosols, and at least of $80 \%$ for the larger aerosols $(1-3 \mu \mathrm{m})$. It seems that the charged proportion is greater for the larger particle sizes, as expected from thermodynamic considerations (Keefe et al., 1959). In contrast, the aerosols seem to be poorly charged in the layer between the tropopause and the middle stratosphere (i.e. between $\sim 8.5 \mathrm{~km}$ and $\sim 20 \mathrm{~km}$ during this flight). The measurements for aerosols greater than $3 \mu \mathrm{m}$ are difficult to interpret accurately, due to the large error bars at low concentrations, but the continued increase with size does seem to remain.

\section{Model}

Model calculations have been used to quantify the electrification of the aerosols with a stratospheric ion-aerosol model in the altitude range of $5-24 \mathrm{~km}$. The ion clusters are produced mainly in the atmosphere by the interaction of galactic cosmic rays with the atmospheric gases, especially in the dense 

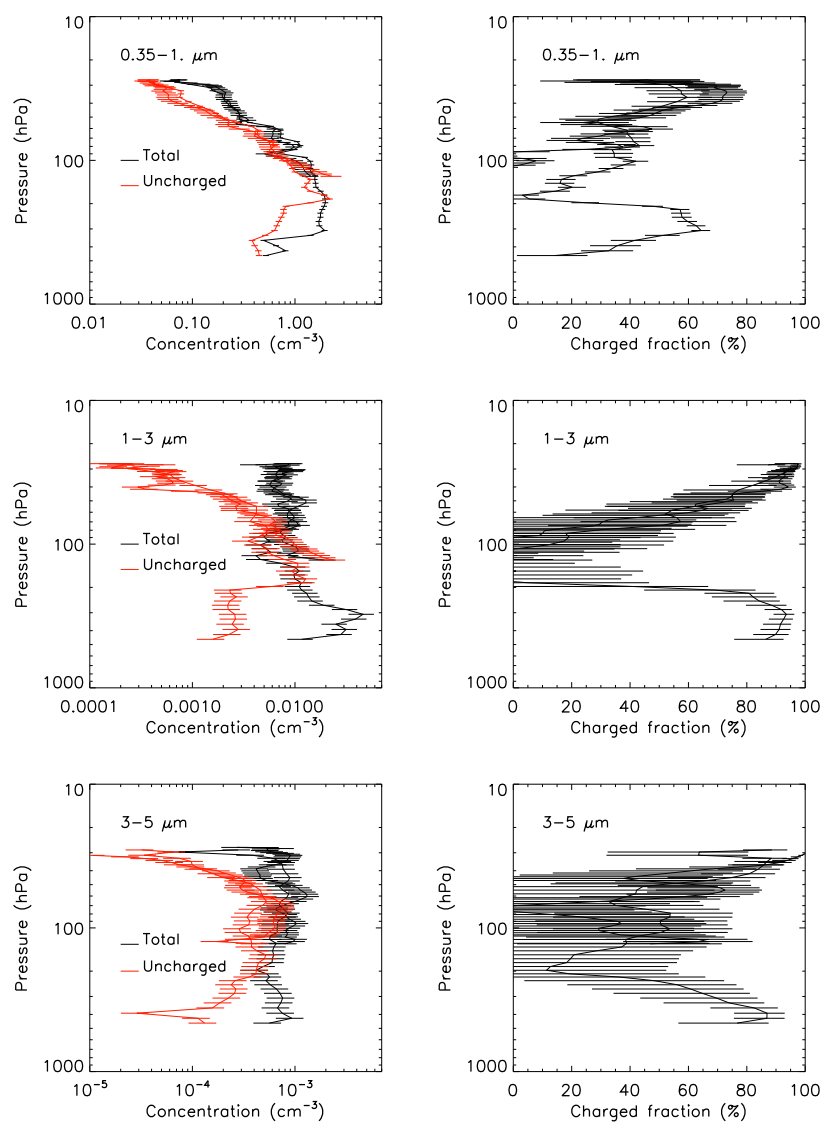

Fig. 2. Left: vertical profiles of integrated concentrations for all the aerosols ("total") and for the uncharged aerosols, during the balloon ascent and the descent, for the 3 size classes. Right: percentage of charges aerosols for the 3 size classes during ascent and descent, taking into account the errors bars on concentrations (a sliding smoothing is applied to suppress small length-scale fluctuations).

regions of the planetary atmospheres where the solar extreme ultraviolet radiation is absent (Harrison and Carslaw, 2003). A significant fraction of the cosmic ray energy flux is typically carried by high-energy particles of kinetic energy of at least $1 \mathrm{GeV}$. The ion production rate by this process peaks at altitudes between 14 and $17 \mathrm{~km}$ (Rawal et al., 2013), and the most abundant ion clusters produced by this process are $\mathrm{SO}_{4}^{-}$ and $\mathrm{NH}_{4}^{+}$.

This ion pair production rate is calculated using the statistical model of O'Brien (2005) with the major ions considered here being $\mathrm{SO}_{4}^{2-}$ and $\mathrm{NH}_{4}^{+}$. Electrons are not included in the model as they recombine with positive ions and uncharged molecules very rapidly, and are consequently not available to interact with aerosols. The charging of aerosols is calculated using charge balance equations as described in Michael et al. (2008, 2009) and Tripathi et al. (2008).

$$
\frac{\mathrm{d} n^{+}}{\mathrm{d} t}=q-\alpha n^{+} n^{-}-\left[n^{+} \sum_{j=r_{1}}^{r_{\text {end }}} \sum_{i=-m}^{m} \beta_{i j}^{+} S_{i j}\right] .
$$

$$
\frac{\mathrm{d} n^{-}}{\mathrm{d} t}=q-\alpha n^{+} n^{-}-\left[n^{-} \sum_{j=r_{1}}^{r_{\text {end }}} \sum_{i=-m}^{m} \beta_{i j}^{-} S_{i j}\right] .
$$

In Eqs. (1) and (2), $n^{+}$and $n^{-}$represent positive and negative ion concentrations, respectively, $q$ is the ion pair production rate, $\alpha$ is the ion-ion recombination coefficient, $S$ is the aerosol concentration, and $\beta$ is the ion-aerosol attachment rate. Here the radii of the aerosols vary from size $r_{1}$ to $r_{\mathrm{end}}$, and the maximum number of elementary charges an aerosol can possess is $m$. The aerosol concentration for any size and charge is calculated by Eq. (3), where $i$ represents the number of elementary charges on a particle for $j$ the associated radius bin.

$$
\begin{aligned}
\frac{\mathrm{d} S_{i j}}{\mathrm{~d} t} & =\beta_{i-1, j}^{+} S_{i-1, j} n^{+}+\beta_{i+1, j}^{-} S_{i+1, j} n^{-} \\
& -\beta_{i, j}^{+} S_{i, j} n^{+}-\beta_{i, j}^{-} S_{i, j} n^{-} .
\end{aligned}
$$

The ion-aerosol attachment coefficients are calculated in different ways depending on the relative size of the particles with the ionic mean free path. The way $\beta$ is calculated depends on the regimes like diffusion, free molecular and transition. Hoppel and Frick (1986) developed a method to calculate $\beta$ in all three different regimes. The major requirements for this calculation are the ionic mobility and mean free path, which are calculated using the expressions from Borucki et al. (1982). Mobility at $5 \mathrm{~km}$ is about $2.5 \times 10^{-4} \mathrm{~m}^{2} \mathrm{~V}^{-1} \mathrm{~s}^{-1}$.

A polydisperse distribution of aerosols is used in the model and is obtained from the STAC measurements of the total aerosol concentration. The neutral atmospheric properties like temperature and pressure measured during the flight are also used in the model. The charge balance equations are solved by a fourth-order Runge-Kutta numerical method, and the concentrations of positive ions, negative ions, uncharged aerosols and charged aerosols are obtained for the steady state.

Figure 3 presents the initial and final ion concentrations from the simulation. As the initial concentrations of positive and negative ions are the same, only positive ion concentrations are shown in the figure. These ions are removed by the ion-aerosol attachment; it is shown that this ion removal is very small for altitudes less than $8 \mathrm{~km}$. The total electrical conductivity of the atmosphere is a function of the concentration of the ions and their mobilities, and is calculated by Eq. (4):

$\sigma=e\left(n_{+} K_{+}+n_{-} K_{-}\right)$,

where $e$ is the electronic charge, $n_{+}$and $n_{-}$are the number densities and $K_{+}$and $K_{-}$are the mobilities of positive and negative ions respectively. About $5-10 \%$ of the ions are removed by the ion-aerosol interactions, thus decreasing the conductivity of the atmosphere. 


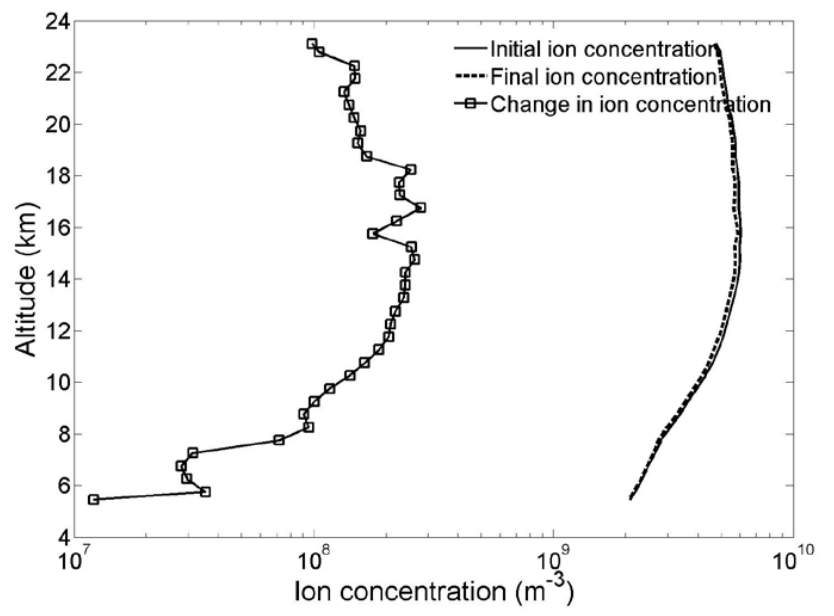

Fig. 3. The initial and final ion concentrations from modelling calculations.

Figure 4 shows the simulated probability of charge distribution on particles at $8 \mathrm{~km}$ in the atmosphere. The probability is calculated by finding the ratio of the concentration of particles with charge to the total concentration in a specific size range. Particles with radii $0.33-1 \mu \mathrm{m}$ can carry only a few charges (i.e. only less than $1 \%$ of the particles can carry charges more than \pm 4 ), and about $20 \%$ of the particles remain neutral. Only $11 \%$ of the particles in the size range $1-3.3 \mu \mathrm{m}$ remain uncharged, and less than $1 \%$ of the particles can carry more than \pm 7 electronic charges. Bigger particles (radius $>3.3 \mu \mathrm{m}$ ) show a flatter charge distribution and carry up to \pm 10 electronic charges. The ion-aerosol attachment coefficients increase with the particle size, and therefore larger particles carry more charges compared to the smaller particles (Tripathi et al., 2008; Michael et al., 2008, 2009). Similar results were observed at other altitudes (not shown here).

According to Fig. 5, the concentration of neutral particles shows a good agreement between the model and the observation below $10 \mathrm{~km}$ and above $20 \mathrm{~km}$ for the particles in the $1-3 \mu \mathrm{m}$ size range. For sub-micron particles and the largest particles, the model underestimates the uncharged particle concentration, although charged particles are detected below $10 \mathrm{~km}$ and above $20 \mathrm{~km}$. In the $10-20 \mathrm{~km}$ altitude range, the model and the observations are inconsistent for all sizes; the observations indicate that most of the particles remain neutral while the simulations show a large percentage of charged particles. Hence we could speculate that a process not represented in the model inhibits electrification in this altitude range. Such a process would have to act to remove the ions present, or greatly increase their mobility, slowing the diffusion charging. It might be associated with the vertical transport and mixing of air masses, and, as already mentioned, we cannot totally exclude the possibility of an unknown instrumental artefact.

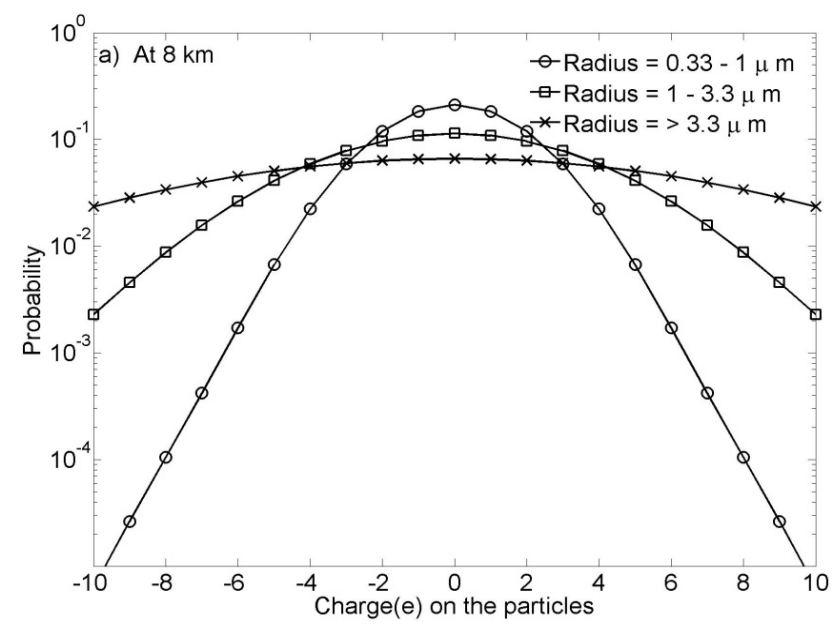

Fig. 4. Probability of charge distribution on aerosols at $8 \mathrm{~km}$ from modelling calculations.

\section{Discussion and conclusion}

Even though it is currently not possible to determine the exact nature of the aerosols, these novel results strongly establish the need for more detailed measurements and modelling. For example, the electric properties of aerosols could depend on their shape, as liquid droplets have a smaller surface area than fractal-shaped particles like soot. This could explain the differences in the agreement between modelling and measurements for the different sizes of aerosols. It is expected that liquid aerosols are associated with sub-micron sizes, and solid particles are associated with larger sizes. Yet, the aerosol is likely to be much more complex because of the presence of soot particles in the submicron and micron size range, thereby increasing the complexity of future modelling work.

The presence of layers of electrified aerosols in the middle stratosphere could have significant implications for sprite formation. Sprites are transient streamer discharges in the atmosphere above thunderclouds (Franz et al., 1990; Sentman et al., 1995). They are caused by impact ionisation resulting from the electromagnetic fields associated with intense positive lightning discharges (e.g. Boccippio et al., 1995; Pasko, 2010). The key parameter to explain sprite initiation is the charge moment change resulting from the lightning continuing current (Cummer and Stanley, 1999; Cummer and Fullekrug, 2001). The threshold for sprite initiation varies by at least a factor of $\sim 2$ or more, which may be explained by nocturnal mesospheric conductivity variations (Cummer and Lyons, 2005), intra-cloud lightning discharges (Ohkubo et al., 2005), or possibly meteoritic dust (Zabotin and Wright, 2001). In either case, it is commonly believed that positive lightning discharges with continuing current are a necessary but not necessarily sufficient condition to initiate sprites. The possible presence of electrified aerosol layers 

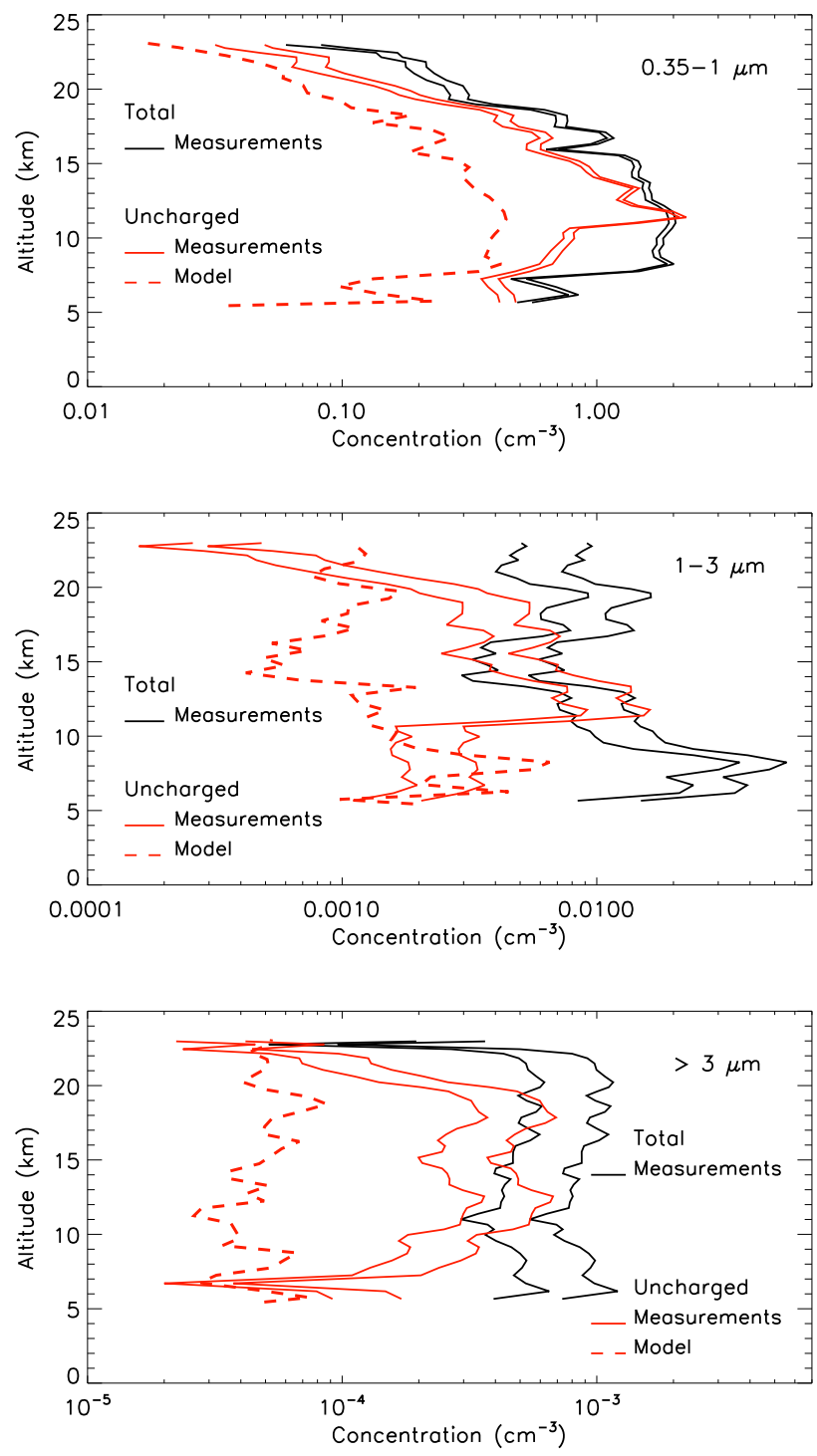

Fig. 5. Comparison between ascent measurements (solid lines) and modelling (dashed lines). The 2 measurement curves represent minimum and maximum values taking into account the error bars. The altitude scale is given in $\mathrm{km}$ for comparison with the altitude scale in Figs. 1 and 2 given in $\mathrm{hPa}$. The modelling data are constrained by the total concentration of aerosols measured by STAC.

in the middle stratosphere as observed here may result in a significant enhancement of the electric field in the middle stratosphere, which reaches up to the stratopause and beyond into the mesosphere and could thereby assist sprite initiation. This hypothesis clearly warrants testing by flying a balloon above or nearby sprite-producing thunderstorms to measure the electrified aerosol content with aerosol counters equipped to detect charged aerosols.
Acknowledgements. The AEROWAVE project is funded by CNES and CNRS/INSU. This work is supported by the Labex Voltaire (ANR-10-LABX-100-01) from University of Orleans. The work at the University of Bath is supported by the Natural Environment Research Council (NERC) under grant NE/H024921/1. The modelling work at IIT, Kanpur, is supported by Ministry of Earth Sciences, India. We thank the CNES balloon launching team for the STAC flight and J.-P. Lebreton (LPC2E-CNRS) for helpful comments. Stratospheric aerosol data and other balloon measurements on stratospheric species are available on the ETHER website: http://ether.ipsl.jussieu.fr/

Edited by: M. Schulz

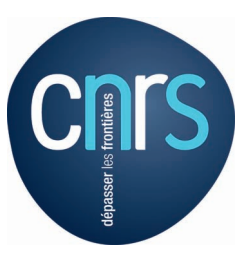

The publication of this article is financed by CNRS-INSU.

\section{References}

Amyx, K., Sternovsky, Z., Knappmiller, S., Robertson, S., Horanyi, M., and Gumbel, J.: In-situ measurement of smoke particles in the wintertime polar mesosphere between 80 and $85 \mathrm{~km}$ altitude, J. Atmos. Sol.-Terr. Phy., 70, 61-70, doi:10.1016/j.jastp.2007.09.013, 2008.

Boccippio, D. J., Williams, E. R., Heckman, S. J., Lyons, W. A., Baker, I., and Boldi, R.: Sprites, ELF Transients and Positive Ground Strokes, Science, 269, 1088-1091, doi:10.1126/science.269.5227.1088, 1995.

Borucki, W. J., Levin, Z., Whitten, R. C. , Keesee, R. G., , Capone, L. A.,, Toon, O. B., and Dubach, J.: Predicted electrical conductivity between 0 and $80 \mathrm{~km}$ in the Venusian atmosphere, Icarus, 51, 302-321, 1982.

Brühl, C., Lelieveld, J., Crutzen, P. J., and Tost, H.: The role of carbonyl sulphide as a source of stratospheric sulphate aerosol and its impact on climate, Atmos. Chem. Phys., 12, 1239-1253, doi:10.5194/acp-12-1239-2012, 2012.

Ciucci, A., Palumbo, P., Brunetto, R., Della Corte,V., De Angelis, S., Rotundi, A., Rietmeijer, F. J. M, Zona, E., Colangeli, L., Esposito, F., Mazzotta Epifani, E., Mennella, V., Inarta, S., Peterzen, S., Masi, S., and Ibba, R.: DUSTER (Dust in Upper Stratosphere Tracking Experiment and Retrieval) preliminary analysis, Mem. S. A. It., 75, 282-287, 2008.

Clement, C. F. and Harrison, R. G.: Charge distributions on aerosols, Inst. Phys. Conf. Ser., 118, 275-280, 1991.

Cummer, S. A. and Füllekrug, M.: Unusually intense continuing current in lightning produces delayed mesospheric breakdown, Geophys. Res. Lett., 28, 495-498, 2001.

Cummer, S. A. and Lyons, W. A.: Implications of lightning charge moment changes for sprite initiation, J. Geophys. Res., 110, A04304, doi:10.1029/2004JA010812, 2005.

Cummer, S. A. and Stanley, M.: Submillisecond resolution lightning currents and sprite development: Observations and implications, Geophys. Res. Lett., 26, 3205, doi:10.1029/1999GL003635, 1999. 
Deshler, T., Hervig, M. E., Hofmann, D. J., Rosen, J. M., and Liley J. B.: Thirty years of in situ stratospheric aerosol size distribution measurements from Laramie, Wyoming $\left(41^{\circ} \mathrm{N}\right)$ using balloon-borne instruments, J. Geophys. Res., 108, D54167, doi:10.1029/2002JD002514, 2003.

Franz, R. C., Nemzek R. J., and Winckler, J. R.: Television Image of a Large upward Electric Discharge above a Thunderstorm System, Science, 249, 48-51, doi:10.1126/science.249.4964.48, 1990.

Fromm, M. and Servranckx, R.: Transport of forest fire smoke above the tropopause by supercell convection, Geophys. Res. Lett., 30, 1542, doi:10.1029/2002GL016820, 2003.

Gabrielli, P., Barbante, C., Plane, J. M., Varga, A., Hong, S., Cozzi, G., Gaspari, V., Planchon, F. A., Cairns, W., Ferrari, C., Crutzen, P., Cescon, P., and Boutron, C. F.: Meteoric smoke fallout over the Holocene epoch revealed by iridium and platinum in Greenland ice, Nature, 432, 1011-1014, doi:10.1038/nature03137, 2004.

Gilbert, J. S., Lane, S. J., Sparks, R. S. J., and Koyaguchi, T.: Charge measurements on particle fallout from a volcanic plume, Nature, 349, 598-600, 1991.

Gunn, R.: Diffusion charging of atmospheric droplets by ions, and the resulting combination coefficients, J. Meteorol., 11, 339-347, 1954.

Harrison, R. G. and Carslaw, K. S.: Ion-aerosol-cloud processes in the lower atmosphere, Rev. Geophys., 41, 1012, doi:10.1029/2002RG000114, 2003.

Harrison, R. G., Nicoll, K. A., Ulanowski, Z., and Mather, T. A.: Self-charging of the Eyjafjallajökull volcanic ash plume, Environ. Res. Lett., 5, 024004, doi:10.1088/1748-9326/5/2/024004, 2010.

Haywood, J. M., Jones, A., Clarisse, L., Bourassa, A., Barnes, J., Telford, P., Bellouin, N., Boucher, O., Agnew, P., Clerbaux, C., Coheur, P., Degenstein, D., and Braesicke, P.: Observations of the eruption of the Sarychev volcano and simulations using the HadGEM2 climate model, J. Geophys. Res., 115, D21212, doi:10.1029/2010JD014447, 2010.

Hervig, M. E, Gordley, L. L., Deaver, L. E., Siskind, D. E., Stevens, M. H., Russell III, J. M., Bailey, S. M., Megner, L., and Bardeen, C. G: First Satellite Observations of Meteoritic Smoke in the Middle Atmosphere, Geophys. Res. Lett., 36, L18805, doi:10.1029/2009GL039737, 2009.

Hoppe, U.-P., Eriksen, T., Thrane, E., Blix, T. A., Fiedler, J., and Lübken, F.-J.: Observations in the polar middle atmosphere by rocket-borne Rayleigh lidar: First results, Earth Planets Space, 51, 815-824, 1999.

Hoppel, W. A. and Frick, G. M.: Ion-aerosol attachment coefficients and the steady-state charge on aerosols in a bipolar ion environment, Aerosol Sci. Tech., 5, 1-21, 1986.

Keefe, D., Nolan, P. J., and Rich, T. A.: Charge equilibrium in aerosols according to the Boltzmann law, Proc. Roy. Irish Acad. A, 60, 27-45, 1959.

Klekociuk, A., Brown, P. G., Pack, D. W., ReVelle, D. O., Edwards, W. N., Spalding, R. E., Tagliaferri, E., Yoo, B. B., and Zagari, J.: Meteoritic dust from the atmospheric disintegration of a large meteoroid, Nature, 436, 1132-1135, doi:10.1038/nature03881, 2005.

Michael, M., Triapthi, S. N., and Mishra, S. K.: Dust charging and electrical conductivity in the day and night- time atmosphere of Mars, J. Geophys. Res., 113, E07010, doi:10.1029/2007JE003047, 2008.

Michael, M., Tripathi, S. N., Borucki, W. J., and Whitten, R. C.: Highly charged cloud particles in the atmosphere of Venus, J. Geophys. Res., 114, E04008, doi:10.1029/2008JE003258, 2009.

Neely, R. R., English, J. M., Toon, O. B., Solomon, S., Mills, M., and Thayer, J. P.: Implications of extinction due to meteoritic smoke in the upper stratosphere, Geophys. Res. Lett., 38, L24808, doi:10.1029/2011GL049865, 2011.

Nicoll, K. A. and Harrison R. G.: Experimental determination of layer cloud edge charging from cosmic ray ionization, Geophys. Res. Lett., 37, L13802, doi:10.1029/2010GL043605, 2010.

Nicoll, K. A., Harrison, R. G., and Ulanoswki, Z.: Observations of Saharan dust layer electrification, Environ. Res. Lett., 6, 014001, doi:10.1088/1748-9326/6/1/014001, 2011.

O'Brien, K.: The theory of cosmic-ray and high-energy solar particle transport in the atmosphere, The natural radiation environment VII, edited by: McLaughlin, J. P., Simopoulos, S. E., and Steinhusler, F., Elsevier, Amsterdam, 2005.

Ohkubo, A., Fukunishi, H., Takahashi, Y., and Adachi, T.: VLF/ELF sferic evidence for in-cloud discharge activity producing sprites, Geophys. Res. Lett., 32, L04812, doi:10.1029/2004GL021943, 2005.

Ovarlez, J. and Ovarlez, H.: Water vapour and aerosol measurements during SESAME, and the observation of low water vapour content layers, Polar Stratospheric Ozone, Proceedings of the Third European Workshop, Air Pollution Rep. 56, edited by: Pyle, J. A., Harris, N. R. P., and Amanatidis, G. T., European Commission, 205-208, 1995.

Pasko, V. P.: Recent advances in theory of transient luminous events, J. Geophys. Res., 115, A00E35, doi:10.1029/2009JA014860, 2010.

Rapp, M.: Charging of mesospheric aerosol particles: the role of photodetachment and photoionization from meteoric smoke and ice particles, Ann. Geophys., 27, 2417-2422, doi:10.5194/angeo-27-2417-2009, 2009.

Rawal, A., Tripathi, S. N., Michael, M., Srivastava, A. K., and Harrison, R. G.: Quantifying the importance of galactic cosmic rays in cloud microphysical processes, J. Atmos. Sol.-Terr. Phy., 102, 243-251, 2013.

Renard, J.-B., Berthet, G., Robert, C., Chartier, M., Pirre, M., Brogniez, C., Herman, M., Verwaerde, C., Balois, J.-Y., Ovarlez, J., Ovarlez, H., Crespin, J., and Deshler, T.: Optical and physical properties of stratospheric aerosols from balloon measurements in the visible and near-infrared domain: 2. Comparison of extinction, reflectance, polarization and counting measurements, Appl. Optics, 41, 7540-7549, 2002.

Renard, J.-B., Brogniez, C., Berthet, G., Bourgeois, Q., Gaubicher, B., Chartier, M., Balois, J.-Y., Verwaerde, C., Auriol, F., Francois, P., Daugeron, D., and Engrand, C.: Vertical distribution of the different types of aerosols in the stratosphere, detection of solid particles and analysis of their spatial variability, J. Geophys. Res., 113, D21303, doi:10.1029/2008JD010150, 2008.

Renard, J.-B., Berthet, G., Salazar, V., Catoire, V., Tagger, M., Gaubicher, B., and Robert, C.: In situ detection of aerosol layers in the middle stratosphere, Geophys. Res. Lett., 37, L20803, doi:10.1029/2010GL044307, 2010.

Schwarz, J. P., Gao, R. S., Fahey, D. W., Thomson, D. S., Watts, L. A., Wilson, J. C., Reeves, J. M., Darbeheshti, M., Baum- 
gardner, D. G., Kok, G. L., Chung, S. H., Schulz, M., Hendricks, J., Lauer, A., Kärcher, B., Slowik, J. G., Rosenlof, K. H., Thompson, T. L., Langford, A. O., Loewenstein, M., and Aikin, K. C.: Single-particle measurements of mid-latitude black carbon and light-scattering aerosols from the boundary layer to the lower stratosphere, J. Geophys. Res., 111, D16207, doi:10.1029/2006JD007076, 2006.

Sentman, D. D., Wescott, E. M., Osborne, D. L., Hampton, D. L., and Heavner, M. J.: Preliminary results from the Sprites94 Aircraft Campaign: 1. Red sprites, Geophys. Res. Lett., 22, 12051208, doi:10.1029/95GL00583, 1995.

Tie, X., Madronich, S., Walters, S., Edwards, D. P., Ginoux, P., Mahowald, N., Zhang, R. Y., Lou, C., and Brasseur, G.: Assessment on the global impact of aerosols on tropospheric oxidants, J. Geophys. Res., 110, D03204, doi:10.1029/2004JD005359, 2005.
Tripathi, S. N., Michael, M., and Harrison, R. G.: Profiles of Ion and Aerosol Interactions in Planetary Atmospheres, Space Sci. Rev., 30, 193-211 doi:10.1007/s11214-008-9367-7, 2008.

Vernier, J.-P., Thomason, L. W., Pommereau, J.-P., Bourassa, A., Pelon, J., Garnier, A., Hauchecorne, A., Blanot, L., Trepte, C., Degenstein, D., and Vargas, F.: Major influence of tropical volcanic eruptions on the stratosphere aerosol layer during the last decade, Geophys. Res. Lett., 38, L12807, doi:10.1029/2011GL047563, 2011.

Zabotin, N. A. and Wright, J. W.: Role of meteoric dust in sprite formation, Geophys. Res. Lett., 28, 2593-2596, doi:10.1029/2000GL012699, 2001. 